\title{
Lung Development in the Streptozotocin Rat Fetus: Antioxidant Enzymes and Survival in High Oxygen
}

\author{
ILENE R. S. SOSENKO AND LEE FRANK \\ Pulomonary Research Laboratories, Calvin and Flavia Oak Asthma Research and Treatment Facility, \\ Department of Medicine and Division of Neonatalogy, Department of Pediatrics, University of Miami School of \\ Medicine, Miami, Florida 33101
}

\begin{abstract}
Offspring of experimentally induced diabetic animals demonstrate delays in functional, biochemical, and morphological aspects of lung maturation, dealing mainly with the surfactant system. To investigate whether the development of the lung antioxidant enzyme system would be similarly delayed, and thus compromise their tolerance to high $\mathrm{O}_{2}$ exposure, we did the following: 1) produced the diabetic state in rats with streptozotocin injection $24 \mathrm{~h}$ after the onset of pregnancy; 2) examined fetal animals from streptozotocin and control rats at gestational days 19 , 20 , and 21 , and newborn animals at day 22 for whole lung disaturated phosphatidylcholine and total phospholipid and for the three antioxidant enzymes: superoxide dismutase, catalase, glutathione peroxidase; and 3) exposed newborn offspring from steptozotocin-treated and control rats to $>95 \% \mathrm{O}_{2}$ for several days and their survival, changes in antioxidant enzymes and disaturated phosphatidylcholine and light microscopic findings in response to hyperoxic challenge were compared. Streptozotocin offspring demonstrated essentially no developmental differences in whole lung disaturated phosphatidylcholine, total phospholipid, or antioxidant enzymes activity at the 4 gestational days studied. However, newborns of streptozotocin mothers had consistently superior tolerance to hyperoxic exposure, consisting of increased survival $[23 / 34(68 \%)$ versus $8 / 26$ $(31 \%)$ in controls, after $\mathrm{O}_{2}$-exposure for 13 days, $p<$ $\mathbf{0 . 0 0 1}$, microscopic evidence of reduced inhibition of alveolarization $(p<0.05)$, and a trend toward greater antioxidant enzymes response. Thus, in this animal model of experimental diabetes, neither the development of the antioxidant enzymes system nor the development of the surfactant system (as assessed by whole lung disaturated phosphatidylcholine and total phospholipid) appear delayed. However, the superior tolerance to hyperoxic exposure in streptozotocin offspring raises the question whether maternal diabetes might actually have a protective influence against $\mathrm{O}_{2}$-induced lung damage in prematurely delivered infants of diabetic mothers. (Pediatr Res 20: 6770, 1986)
\end{abstract}

\section{Abbreviations}

IDM, infants of diabetic mothers HMD, hyaline membrane disease STZ, streptozotocin

Received June 12, 1985; accepted August 21, 1985.

Correspondence and reprint requests to Ilene R. S. Sosenko, M.D., University of Miami School of Medicine, Pulmonary Research R120, P.O. Box 016960, Miami, FL 33101.

Supported in part by NIH Grants HL072383, HL26029. LF was an NHLBI Research Career Development Awardee (HLO1230) during the course of this study.
DSPC, disaturated phosphatidylcholine

Lm, mean linear intercept

IDM have a 6-fold increased risk of developing HMD compared to infants whose mothers are not diabetic (1). This increase in HMD has been attributed to a delay in lung maturation in the IDM. Numerous animal studies both in vivo and in vitro have reported delays in functional, biochemical, and morphological lung development in the IDM, focusing mainly on the surfactant system and the differentiation of the type II epithelial cell (2-7). Those infants of diabetic mothers who develop HMD usually require treatment with increased concentrations of inspired oxygen. The antioxidant enzyme system of the lung, consisting in part of superoxide dismutase, catalase, and glutathione peroxidase, is an important defense against free radicals and other toxic $\mathrm{O}_{2}$ metabolites produced intracellularly in excess amounts during exposure to hyperoxia. The development of the pulmonary antioxidant enzyme system in fetal animals has recently been found to accelerate in late gestation, in a pattern chronologically similar to the development of the surfactant system (8). Because of the evidence for a delay in maturation of the surfactant system in the IDM, we questioned whether the development of the antioxidant enzyme system would be similarly delayed, thus putting the IDM at increased risk for $\mathrm{O}_{2^{-}}$ induced lung damage (bronchopulmonary dysplasia) in addition to HMD. We report here the developmental profile of both of these biochemical systems in offspring of STZ-diabetic rats as well as the comparative tolerance to and survival during hyperoxic exposure of IDM and control newborn rat pups.

\section{METHODS}

Animals. Adult Sprague-Dawley albino female rats ( 250 g) were bred by placing male and female together overnight, checking for sperm-positive vaginal smears the following morning, and considering the midpoint of the cohabitation period as the onset of pregnancy. Twenty four hours following confirmation of pregnancy, rats were selected at random to receive streptozotocin (Sigma Chemical Co.) intraperitoneally $(65 \mathrm{mg} / \mathrm{kg}$ ) or saline.

General features of the streptozotocin-induced diabetic state. Maternal blood glucose was determined at delivery using the glucose oxidase method (9).

STZ and control offspring were followed with daily weights over the first 10 days of life to examine comparative postnatal growth. During this time, mixed litters were placed with surrogate (nondiabetic) mothers to eliminate potential poor mothering induced by the STZ-diabetic state. 
Development of the surfactant and antioxidant enzyme systems. Either at birth (22 days) or at preterm delivery (days 19, 20 , or 21) animals from both groups were sacrificed for lung biochemical studies. Maternal animals (or their offspring if they had delivered) received a lethal intraperitoneal injection of pentobarbital. Fetal lungs were perfused immediately in situ via the pulmonary artery using cold saline, and homogenized in 20$30 \times$ their weight of cold saline in a Brinkman polytron (high speed, $90 \mathrm{~s}$ ). For preterm or small newborns, two to four lungs were pooled to obtain adequate tissue for the assays. Enzyme analysis was done using standard spectrophotometric assays for SOD (10), CAT (11), and GP (12). Purified enzyme standards for each assay were obtained from Sigma (SOD, CAT) and Boehringer Mannheim, Co. (GP). Results of enzyme analyses were expressed as units of enzyme activity per mg DNA as well as per $\mathrm{mg}$ protein and per $\mathrm{g}$ lung. DNA (13), protein (14), and RNA (15) assays have been described elsewhere as has the lipid extraction of lung homogenate (16), analysis of DSPC (17) and assay for inorganic phosphorus $(18,19)$.

Exposure to hyperoxia. Multiple litters of newborns of streptozotocin-treated and control rats were removed from their mothers shortly after birth, marked by toe clipping, and placed together as mixed litters (10-12 per dam) with surrogate, uninjected newly delivered mother rats to eliminate potential variables in mothering and nursing capabilities brought on by the STZ-diabetic state. At approximately $6-12 \mathrm{~h}$ of life, the mixed litters began exposure to $>95 \% \mathrm{O}_{2}$ (or room air). Details of the exposure conditions have previously been reported (19). Surrogate mothers were rotated between the room air and $>95 \% \mathrm{O}_{2}$ litters every $24 \mathrm{~h}$ to prevent $\mathrm{O}_{2}$-induced illness with consequent poor mothering. Survival of newborns from each group was recorded daily as were daily weights for the 13-day exposure period. At day 5 of exposure, several randomly chosen STZ and control offspring were sacrificed and lungs assayed for phospholipids and antioxidant enzymes as described above. Others from both groups were sacrificed and had their lungs fixed with $10 \%$ buffered formalin, infused via a tracheal cannula using a constant inflation pressure of $20 \mathrm{~cm}$ of water (fixative). Similarly oriented sections from both groups of lungs were taken for hematoxylin and eosin light microscopic slide prepration. Light microscopic morphometry was performed utilizing an integrating grid eye piece with five equal lines and 25 intercept bars (Zeiss). No correction was made for tissue shrinkage. At $450 \times$ magnification, we counted the number of times lines were crossed by tissue septa per field. Thirty random fields were examined from each lobe. Lm was calculated using the formula (20):

$$
\mathrm{Lm}=\frac{\text { length of line }(0.21 \mu \mathrm{m}) \times \text { no. of lines } \times \text { no. of fields }}{\text { no. of tissue intercepts }}
$$

Tabulation was also performed of mean number of developing septae or septal buds crossed by the grid lines.

Statistics were performed using Student's $t$ test and 2-way analysis of variance (when comparing several litters of the same gestational age exposed to the same experimental conditions) (21).

\section{RESULTS}

General features of the STZ-induced diabetic state in the rat. Mean maternal blood sugar prior to delivery was $434 \pm 183 \mathrm{mg} /$ dl $(n=15)$ for STZ-injected rats and $128 \pm 28(n=5)$ for controls, $p<0.05$. STZ-injected rats with hyperglycemia demonstrated grossly lipemic serum and the majority appeared healthy despite marked hyperglycemia (and without insulin therapy).

Body weights of term newborn STZ offspring were significantly lower than controls $(5.50 \pm 1.12$ versus $6.52 \pm 0.63 \mathrm{~g},-16 \%, p$ $<0.05$ ). A similar relationship for body weights was present at all gestational ages studied (days 19, 20, and 21). The growth curves of STZ and control offspring over the first 10 days of life are seen in Figure 1. STZ offspring begin life at a lower weight and continue to grow in a parallel fashion to control offspring, without evidence of catch-up growth during this time period. In addition, growth of $\mathrm{O}_{2}$-exposed STZ offspring does not differ significantly from air-exposed STZ offspring and no difference in growth is present between $\mathrm{O}_{2}$ and air-exposed controls (Fig. 1).

Developmental biochemistry. DNA and RNA content were not significantly different between streptozotocin and control offspring at all four gestational ages studied. Lung protein was significantly decreased in the STZ offspring compared to controls at days $20(8.77 \pm 1.85$ versus $10.46 \pm 1.04 \mathrm{mg} / \mathrm{lung}), 21(12.48$ \pm 1.47 versus $18.21 \pm 1.19)$, and $22(15.04 \pm 1.59$ versus 18.02 \pm 2.19 ), all values $p<0.05$. For the three antioxidant enzymes, no values were statistically different between the two groups at any gestational age studied (whether expressed per gram of lung, per mg protein or per mg DNA) except for decreased SOD $(\downarrow 13 \%)$ activity in 20-day-old STZ fetal lungs (Table 1$)$. Furthermore, values for DSPC and total phospholipid (and DSPC/total phospholipid) were not different between groups at days 19-22 (Table 1).

Exposure to hyperoxia. Composite survival data from three separate experiments are depicted in Figure 2. Beginning on the 8 th day of hyperoxic exposure, STZ pups had significantly greater survival rates than control pups. On day 8,27 of 34 (79\%) STZ offspring were alive, compared to 15 of $26(58 \%)$ controls, $p<$ 0.05 ; by day 13 of hyperoxia, 23 of $34(68 \%)$ STZ offspring were still living, compared to only 8 of $26(31 \%)$ controls, $p<0.001$.

Antioxidant enzymes and DSPC measured in control offspring exposed to air for 5 days (to give baseline values) and compared to both STZ and control offspring exposed to 5 days of $>95 \%$ $\mathrm{O}_{2}$ are listed in Table 2. While differences in the magnitude of the lung enzyme response to $\mathrm{O}_{2}$-challenge between the $\mathrm{O}_{2}$-exposed STZ offspring and $\mathrm{O}_{2}$-exposed controls does not reach statistical significance, mean CAT and GP activities were slightly higher in the STZ offspring in response to hyperoxic exposure. Values for DSPC did not differ between groups.

Lung light microscopic morphometry, specifically Lm (baseline value: $1.297 \pm 0.45 \mu \mathrm{m}$ in air controls), demonstrated an increase in average size of airspaces following 5 days of hyperoxic exposure in both STZ and control offspring, with significantly smaller increase in mean airspace size in $\mathrm{O}_{2}$-exposed streptozotocin offspring $(1.455 \pm 0.146, \uparrow 12 \%)$ compared to $\mathrm{O}_{2}$-exposed control pups $(1.870 \pm 0.008, \uparrow 44 \%), p<0.05$. Quantitation of developing alveolar-septal buds demonstrated a decrease with

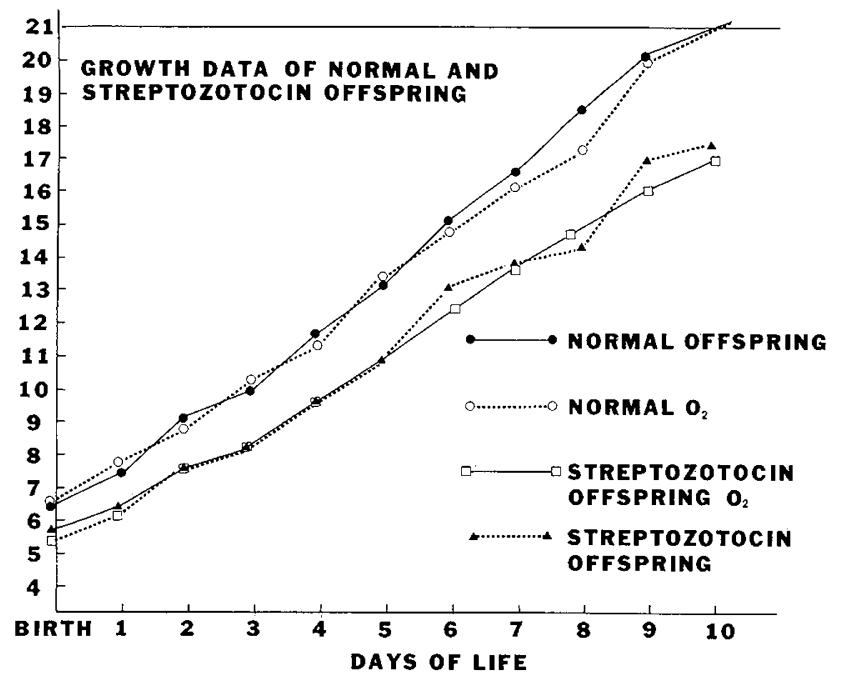

Fig. 1. Growth curves: $\mathrm{SrZ}$ and control newborn rats and $\mathrm{O}_{2}$-exposed STZ and control newborns (continuous $\mathrm{O}_{2}$ exposure, $>95 \%$ ). 
Table 1. Developmental changes in antioxidant enzymes and DSPC (mean $\pm S D)^{*}$

\begin{tabular}{|c|c|c|c|c|c|c|c|c|}
\hline \multirow[b]{2}{*}{ Gestational Age } & \multicolumn{2}{|c|}{$\mathrm{SOD} \dagger$} & \multicolumn{2}{|c|}{ CAT $\dagger$} & \multicolumn{2}{|c|}{$\mathrm{GP}_{\dagger}$} & \multicolumn{2}{|c|}{$\mathrm{DSPC} \dagger$} \\
\hline & STZ & Cont & STZ & Cont & STZ & Cont & STZ & Cont \\
\hline 19 & $28.8 \pm 2.4$ & $34.1 \pm 8.8$ & $182 \pm 24$ & $274 \pm 76$ & $1.52 \pm .25$ & $1.54 \pm .20$ & $2.23 \pm 0.60$ & $2.41 \pm 0.59$ \\
\hline 21 & $47.7 \pm 4.7^{\circ}$ & $51.2 \pm 1.0$ & $535 \pm 130$ & $455 \pm 32$ & $2.01 \pm .12$ & $2.12 \pm .37$ & $4.86 \pm 1.18$ & $4.47 \pm 0.52$ \\
\hline 22 & $56.5 \pm 9.3$ & $53.1 \pm 13.8$ & $805 \pm 196$ & $763 \pm 28$ & $3.55 \pm .39$ & $3.34 \pm 1.08$ & $4.94 \pm 0.47$ & $4.42 \pm 0.93$ \\
\hline
\end{tabular}

* 19 days-three experiments (three to four samples/group/experiment); 20 days-three experiments (three samples/group/experiment); 21 days-two experiments (three to six samples/group/experiment); 22 days—four experiments (three to five samples/group/experiment).

$\dagger$ Units for SOD—U/mg DNA; CAT—IU/mg DNA; GP— $\mu \mathrm{mol} \mathrm{NADPH} \mathrm{oxidized/min/mg} \mathrm{DNA;} \mathrm{DSPC—} \mathrm{mg} / \mathrm{g}$ lung.

$\ddagger p<0.05$, all other values not significant; statistics performed using 2-way analysis of variance.

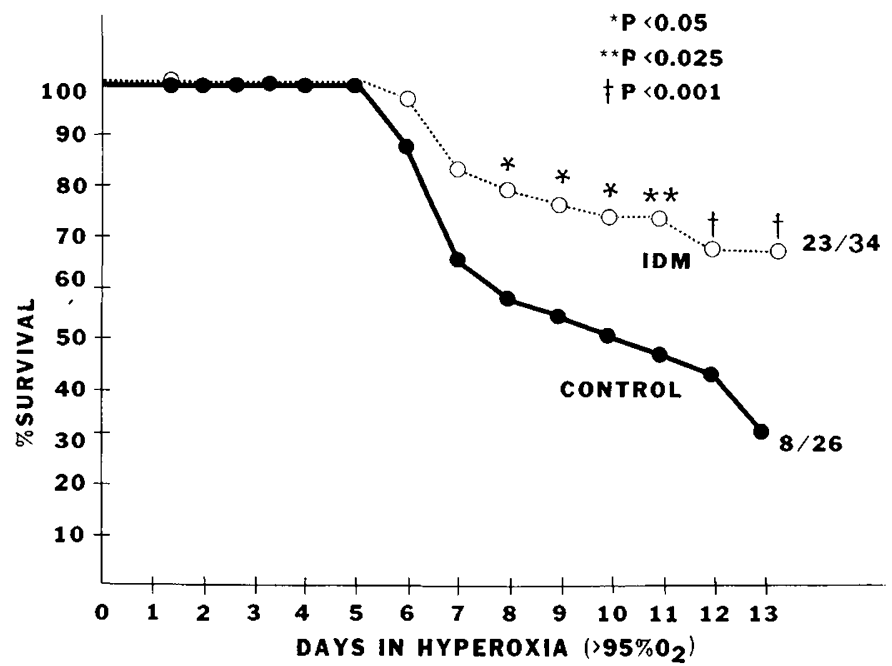

Fig. 2. Survival of newborn STZ (IDM) and control offspring during continuous exposure to $-95 \% \mathrm{O}_{2}$.

$>95 \% \mathrm{O}_{2}$ exposure in both groups compared to air control lungs ( $4.7 \pm 0.3$ septal buds/high power field), but no difference was observed between $\mathrm{O}_{2}$-exposed STZ offspring $(2.2 \pm 0.1)$ and $\mathrm{O}_{2}$ exposed controls $(2.1 \pm 0.1)$.

\section{DISCUSSION}

DSPC and antioxidant enzymes in the IDM. We have demonstrated no decreases in whole lung DSPC or TPL content, nor differences in antioxidant enzyme activities in offspring of STZ rats compared to control rat pups at term and during the final 3 days of gestation, when accelerated maturation of these two lung systems normally occurs. Multiple studies cited in the literature have produced conflicting results in regard to lung surfactantrelated phospholipids, specifically DSPC, in fetuses of experimentally induced diabetic animals $(22,23)$. For example, Gewolb et al. (6) reported decreased amounts of DSPC in fetal rat lung tissue on day 21 only, with no alteration in the activity of enzymes involved in phospholipid synthesis. Our findings of unaltered lung DSPC content in diabetic offspring on days 19 , 20 , and 22 of gestation are consistent with those of Gewolb et al. (6); however, our findings on day 21 are in contrast to theirs. Our DSPC results in offspring of STZ-diabetic rats are in agreement with findings of no difference in DSPC content or incorporation of radiolabeled choline into PC and DSPC in another diabetic animal model, the offspring of alloxan-diabetic rabbits $(3,4)$.

In addition to studies examining pulmonary phospholipid content in diabetic offspring, other studies have demonstrated evidence of delay in other aspects of lung maturation - decreased deflation stability, immature cellular or ultrastructural lung maturation, and delay in glycogenolysis $(3,6,7)$. No previous study that we are aware of has examined the maturation of the antioxidant enzyme system in diabetic offspring. We questioned whether antioxidant enzyme development might also be delayed in diabetic offspring and thus compromise their tolerance to high- $\mathrm{O}_{2}$ exposure. We did not find the anticipated developmental delay in the lungs of our STZ rat offspring. We might postulate from our data that the mechanisms involved with antioxidant enzyme development and surfactant development have similarities in this animal model, i.e. neither appears to be influenced by the STZ-induced diabetic state. To support this idea that the development of the surfactant and antioxidant enzyme systems may share common controlling mechanisms in the fetal lung, it has been recently demonstrated that glucocorticoid treatment of pregnant rats accelerated maturation of both lung DSPC and antioxidant enzyme content in their late fetal offspring (19) and that blockade of endogenous glucocorticoid synthesis (with metyrapone) results in delayed maturation of fetal lung DSPC and antioxidant enzymes (24).

Animal model of the IDM. The animal model of STZ-induced diabetes in the rat and other species has been recently reviewed by Bourbon and Farrell (25). Our findings of marked maternal hyperglycemia associated with depressed growth in utero are in agreement with several investigators $(6,21,25,26)$. This experimental model, therefore, does not reproduce the macrosomia often seen in the human IDM nor the fetal hyperinsulinemia. The growth pattern noted in our STZ offspring is similar to that recently described for intrauterine growth-retarded rats, produced by maternal nutritional deprivation (27). Since our maternal STZ rats lost rather than gained weight during pregnancy, presumably due to their chemically induced hypoinsulin state, the STZ offspring may also have been exposed to relative maternal malnutrition.

Increased $\mathrm{O}_{2}$ tolerance in the IDM. Despite the fact that we found no differences in baseline antioxidant enzymes or DSPC content in newborn STZ offspring compared to controls, we consistently found an unexpectedly superior tolerance to hyperoxia in the diabetic offspring. We found that the STZ newborns were capable of a normal protective lung enzyme response to $\mathrm{O}_{2}$. After 5 days of high $\mathrm{O}_{2}$-exposure, $\mathrm{STZ}$ pup lungs demonstrated a significant preservation of lung architecture, with the Lm nearly similar to air-breathing controls (up only $12 \%$ ), contrasted to the significantly greater $\mathrm{Lm}(\uparrow 44 \%)$ in $\mathrm{O}_{2}$-exposed control neonatal lungs. The increase in average airspace size compared to the lungs of air control pups is believed to reflect $\mathrm{O}_{2}$-induced inhibition of alveolarization, which is also evidenced by inhibited septal bud development $(28,29)$. Whether the improved survival in hyperoxia in STZ newborns relates to a slightly increased lung antioxidant response to hyperoxic challenge or to the marked reduction in inhibition of lung structural development (alveolarization) during $\mathrm{O}_{2}$ exposure is not known.

Other factors that are presumed to play potentially important roles in tolerance to hyperoxia, including vitamin $\mathrm{E}$, glutathione, selenium, and fatty acid composition of cell membranes (30) have not been examined in this animal model. Fatty acid status in STZ offspring would be of particular interest to explore. Placental transfer of triglycerides and free fatty acids is reported to be increased in pregnant diabetic rats (31). Whether these fatty acids are mainly saturated or unsaturated is not yet clarified. The 
Table 2. Antioxidant enzymes and DSPC changes after 5 days of hyperoxia (mean $\pm S D$ )

\begin{tabular}{clccc}
\hline Group $^{*}$ & \multicolumn{1}{c}{ SOD } & \multicolumn{1}{c}{ CAT } & GP & DSPC \\
\hline Air control & $24.6 \pm 3.3$ & $677 \pm 117$ & $1.11 \pm 0.12$ & $2.31 \pm 0.38$ \\
$\mathrm{O}_{2}$ control & $35.1 \pm 4.0(\uparrow 43 \%) \dagger$ & $1220 \pm 110(\uparrow 80 \%)$ & $3.29 \pm 0.14(\uparrow 195 \%)$ & $2.28 \pm 0.22(\downarrow 1 \%)$ \\
$\mathrm{O}_{2}$ STZ & $35.9 \pm 3.4(\uparrow 46 \%)$ & $1369 \pm 220(\uparrow 102 \%)$ & $3.75 \pm 0.39(\uparrow 236 \%)$ & $2.36 \pm 0.45(\uparrow 2 \%)$ \\
\hline
\end{tabular}

* $n=3:$ air control; $n=4: \mathrm{O}_{2}$ control; $n=6: \mathrm{O}_{2} \mathrm{STZ}$.

$\dagger$ Numbers in parentheses represent percentage change compared to air-control values.

composition of saturated versus unsaturated fatty acids in the lung has been reported to affect relative hyperoxic tolerance and relative susceptibility to $\mathrm{O}_{2}$-induced lipid peroxidation $(32,33)$.

Our STZ rat pups, despite reduced newborn body weights and postnatal growth patterns similar to those recently reported for intrauterine growth-retarded rat pups manifested increased $\mathrm{O}_{2}$ tolerance, rather than the markedly decreased $\mathrm{O}_{2}$ tolerance described for the intrauterine growth-retarded pups. These comparative findings are of interest also since in the intrauterine growth-retarded pups, in contrast to our STZ pups, $\mathrm{O}_{2}$-exposure produced a very pronounced inhibition of normal lung development (26). Our findings of superior tolerance to hyperoxia in STZ rat pups raise the unexplored clinical question of whether the maternal diabetic state might actually be associated with some degree of protection against $\mathrm{O}_{2}$-induced lung damage in premature IDM's.

\section{REFERENCES}

1. Robert MF, Neff RK, Hubbell JP, Taeusch HW, Avery ME 1976 Association between maternal diabetes and the respiratory distress syndrome in the newborn. N Engl J Med 294:357-360

2. Bose CL, Manne DM, D'Ercole AJ, Lawson EE 1980 Delayed fetal pulmonary maturation in a rabbit model of the diabetic pregnancy. J Clin Invest 66:220 226

3. Sosenko IRS, Lawson EE, Demottaz V, Frantz ID 1980 Functional delay in lung maturation in fetuses of diabetic rabbits. J Appl Physiol 48:643-647

4. Demottaz V, Epstein MF, Frantz ID 1980 Phospholipid synthesis in lung slices from fetuses of alloxan diabetic rabbits. Pediatr Res 14:47-49

5. Sosenko IRS, Hartig-Beeken I, Frantz ID 1980 Cortisol reversal of functional delay of lung maturation in fetuses of diabetic rabbits. J Appl Physiol 49:971-

6. Gewolb IG, Barret C, Wilson CM, Warshaw JB 1982 Delay in pulmonary glycogen degradation in fetuses of streptozotocin diabetic rats. Pediatr Res 16:869-873

7. Gross I, Walker-Smith GJ, Wilson CM, Maniscalco WM, Ingleson LD, Brehier A, Rooney SA 1980 The influence of hormones on the biochemical development of fetal rat lung in organ culture. II. Insulin. Pediatr Res 14:834838

8. Frank L, Groseclose EE 1984 Preparation for birth into an $\mathrm{O}_{2}$-rich environment: the antioxidant enzymes in the developing rabbit lung. Pediatr Res $18: 240-244$

9. Marks V 1959 An improved glucose-oxidase method for determining blood, CSF and urine glucose. Clin Chim Acta 4:395-400

10. McCord JM, Fridovich I 1969 Superoxide dismutase: an enzymatic function for erythrocuprein (hemocuprein). J Biol Chem 244:6049-6055

11. Holmes RS, Masters CJ 1970 Epigenetic interconversion of the multiple forms of mouse liver catalase. FEBS Lett 11:45-48

12. Paglia DE, Valentine WN 1967 Studies in the quantitative and qualitative characterization of erythrocyte glutathione peroxidase. J Lab Clin Med 70:158-159

13. Richards GM 1974 Modifications of the diphenylamine reactions giving increased sensitivity and simplicity in the estimation of DNA. Anal Biochem 57:369-376

14. Schacterle RE, Pollack RL 1973 A simplified method for the quantitative assay of small amounts of protein in biological material. Anal Biochem 51:654655

15. Schneider WC 1956 Determination of nucleic acid in tissues by pentose analysis. Methods Enzymol 3:680-684

16. Bligh EF, Dyer WJ 1959 A rapid method of total lipid extraction and purification. Can J Biochem Physiol 37:911-917

17. Mason RJ, Nellenbogen J, Clements JA 1976 Isolation of disaturated phosphatidylcholine with osmium tetroxide. J Lipid Res 17:281-284

18. Morrison WR 1964 A fast, simple and reliable method for the microdetermination of phosphorous in biological materials. Anal Biochem 11:218-224

19. Frank L, Lewis PL, Sosenko IRS 1985 Dexamethasone stimulation of fetal rat lung antioxidant enzyme activity in parallel with surfactant stimulation. Pediatrics 75:569-574

20. Thurlbeck WM, Galaugher W, Mathers J 1981 Adaptive response to pneumonectomy in puppies. Thorax 36:424-427

21. Fisher RA 1970 Statistical Methods for Research Workers. Hafner Press, New York, pp 213-301

22. Rhoades RA, Filler DA, Vannata B 1979 Influence of maternal diabetes on lipid metabolism in neonatal rat lung. Biochim Biophys Acta 572:132-138

23. Boutwell WL, Goldman AS 1979 Depressed biochemical lung maturation and steroid uptake in an animal model of infant of diabetic mother. Pediatr Res 13:235(abstr)

24. Sosenko 1, Lewis PL, Frank L 1985 Metyrapone delays maturation of fetal lung surfactant and antioxidant enzymes: Are both under endogenous glucocorticoid control? Pediatr Res 19:1838(abstr)

25. Bourbon JR, Farrell PM 1985 Fetal lung development in the diabetic pregnancy. Pediatr Res 19:253-267

26. Tyden O, Berne C, Eriksson U 1980 Lung maturation in fetuses of diabetic rats. Pediatr Res 14:1192-1195

27. Frank L, Lewis PL, Garcia-Pons T 1985 Intrauterine growth-retarded rat pups show increased susceptibility to pulmonary $\mathrm{O}_{2}$ toxicity. Pediatr Res 19:281286

28. Frank L, Groseclose EE 1982 Oxygen toxicity in newborn rats: the adverse effects of undernutrition. J Appl Physiol 53:1248-1255

29. Roberts RJ, Weesner KM, Bucher JR 1985 Oxygen-induced alterations in lung vascular development in newborn rat. Pediatr Res 17:368-375

30. Forman HJ, Fisher AB 1981 Antioxidant defenses. In: Gilbert DL (ed) Oxygen and Living Processes: An Interdisciplinary Approach. Springer Verlag, New York, pp 235-249

31. Shafrir E, Khassis S 1982 Maternal-fetal fat transport versus new fat synthesis in the pregnant diabetic rat. Diabetologia 22:111-117

32. Kehrer JP, Autor AP 1978 The effect of dietary fatty acids on the composition of adult rat lung lipids: relationship to oxygen toxicity. Toxicol Appl Pharmacol 44:423-430

33. Boyd MR, Catignani GL, Sasame HA, Mitchell JR, Stiko AW 1979 Acute pulmonary injury in rats by nitrofurantoin and modification by Vitamin $\mathrm{E}$, dietary fat, and oxygen. Am Rev Respir Dis 120:93-99 